\title{
Acidic pit lakes - The legacy of coal and metal surface mines
}

\author{
Walter GELLER, Martin SCHULTZE, Robert KLEINMANN, Christian WOLKERSDORFER (eds) Springer, \\ Heidelberg, New York, Dordrecht, London, 2013. \\ ISSN 1431-6250. ISBN 978-3-642-29383-2, ISBN 978-3-642-29384-9 (eBook) xvii + 525 pp. Hardback £ 117.00
}

This book brings together a huge amount of information on acidic pit lakes, ranging from geological aspects, through chemistry to biology to management and longterm control. Broader understanding is increased by brief entries on related topics, such as highly acidic environments associated with volcanoes or mine-influenced lakes which are not acidic. It follows a previous book, Acidic Mining Lakes: Acid Mine Drainage, Limnology and Reclamation, edited by W. Geller, H. Klapper and W. Salomons (1998, Springer). Much of what it is important in that book is integrated into accounts in the present book, although the editors emphasize that there is considerable new knowledge and understanding for a range of topics such as the limnophysical character of pit lakes, interactions between organisms and sediments, and detailed case and regional studies.

The accounts are grouped in six main chapters, with different teams of authors writing the detailed sections or further subsections where these are included. One or more of the editors contributed to many of the sections and two of them, Geller and Schultze wrote both the opening and final chapters. Thirty-nine other authors are involved. The consolidated references listed near the end of the book $(62$ pages) are followed by three indices (General Terms; Mine, Lakes and Streams; Organisms and Taxa).

The introductory Chapter 1 provides a useful background for anyone new to the subject. Such a reader might well find it helpful also to consult the final chapter by the same two authors before tackling the rest of the book, even though they should eventually read the latter again. Chapter 2 Terrestrial Environments of Pit Lakes deals with morphology, age and development and then the influence of groundwater, while Chapter 3 Limnology of Pit Lakes describes their general properties, with sections on physics, chemistry, biology and ecosystem properties, and modelling. The emphasis on physical features is on those not usually covered sufficiently in general texts on limnology. The chemistry of coal and lignite lakes is reviewed separately from that of hardrock metal mine lakes. Both accounts contain a great deal of information and the reader needs to read both get a clear understanding. In fact I had to read the latter before the lignite section and then consult the hardrock subsection once more before being really sure of everything. The subsection on biology and ecosystems is one of the longest in the book, but includes four sets of authors. As the literature comes from the very diverse sources, it is helpful to have so much information in one place, though some of the topics would benefit from longer and much more critical reviews. Fortunately, the final section on modelling (D.S. Dunbar) is written very clearly and provides a helpful background to the detailed case studies in a later chapter.

Chapter 4 Remediation and Management of Acidified Pit Lakes and Outflowing Waters deals with practical matters such as chemical treatment with lime or soda ash (sodium carbonate). Such methods can be effective, but require considerable resources. For instance, Lake Bockwitz, the largest German pit lake, has been completely neutralized by the addition of alkaline substances, but still requires frequent addition of soda ash to prevent re-acidification. The effective distribution of the neutralizing agents can be a challenge. In spite of encouraging results from laboratory experiments with some proposed biological methods such as microbial sulphate reduction, the results of field studies have been much less satisfactory. However, the addition of large amounts of organic matter to Anchor Hill Pit Lake, South Dakota, where the $\mathrm{pH}$ had already been raised to $5.0-5.5$ by the addition of lime, proved successful, because it was possible to maintain the lake in a meromictic condition. Meromictic lakes have also been used in other ways to minimize acidity problems, whether by modifying processes in the lake as a whole or finding ways of dealing with the acid mine drainage as it enters a lake. Section 4.6 Avoidance and Source Treatment (F. Wisotzky) outlines approaches to minimizing problems at even earlier stages.

Chapter 5 "Case Studies and Regional Surveys" comprises one-third of the book and for me was the most useful, as the various authors always provide well-argued reviews rather than the condensed information in some sections of other chapters. The various accounts are for (5.1), (5.6) and (5.8) Germany, (5.2) Poland, (5.3) Spain and Portugal, (5.4) Australia, (5.5) Berkeley Pit Lake, Butte, Montana, and (5.7) Canada. Section 5.9 The Economics of Mine Pit Restoration (N. Lienhoop and F. Messner) considers a different aspect, focussing on Lusatia, which became the centre for energy production during the former German Democratic Republic.

The final chapter (6) highlights some of the main topics in the book, including the ways that treatment methods which have shown some success could be improved, such as those for distributing the materials used for treating acid pit lakes. The authors comment that it is essential to judge the success of remediation approaches on an appropriate 
time perspective. Chemical treatment processes show immediate results in contrast to usually slower improvements with biological processes. When measures for reducing sulphide mineral oxidation are integrated properly into the waste management area, the waste will recover.

The biggest challenge for the reader is that some topics are considered in several different places and the various contributors do not always agree. This may be inevitable for a topic where much of the research has been targeted on solving practical problems, but it emphasizes that caution is needed in quoting information in abstracts of earlier papers and reports without reading the whole text thoroughly and considering critically the experimental procedures and how the data are interpreted. For instance, I was uneasy about some of the comments on phosphate in the water column and how this influences phototrophs. In cases such as the river and lake downstream of Caviahue, the Andes volcano, phosphate is in great excess, but in general $\mathrm{P}$ appears to be in relatively short supply for phototrophs in highly acidic environments. P limitation is mentioned by several contributors. However, values for phosphate concentration are given in different places as soluble reactive phosphate and/or total phosphate. There is only brief mention of organic phosphate, yet it seems likely this is the main form of phosphate in many highly acidic waters much above pH 3.0 (see N.T.W. Ellwood and B.A. Whitton, 1997, Hydrobiologia 575: 96-107). Organic phosphate is probably important for some of the algae mentioned and I was especially uneasy about some of the comments in the main subsection on Zygnematalean algae. No mention is made anywhere of bryophytes, yet mosses and, to a lesser extent liverworts, are frequent in many highly acidic environments, though often only as filamentous stages (protonema). Perhaps bryophytes are slower than algae to invade new acidic environments such as pit lakes.

Another topic which remains unclear is whether or not cyanobacteria occur in these environments. Mainstream literature on cyanobacteria has always agreed that cyanobacteria are absent in environments below $\mathrm{pH} 3.0$ and there do not appear to be convincing records of cyanobacteria having much role in habitats below the range $3.8-4.2$ and in even these cases they are low acidity environments. There are several old reports of narrow filamentous cyanobacteria in Polish pit lakes, but the lack of any proper description has led to them being ignored. In the present book Katrin Wendt-Potthoff (subsection 3.3.1.3) states that live cyanobacteria have not so far been reported from acidic pit lakes, but related sequences have been detected in PCR products obtained with universal bacterial primers following DGGE and sequencing. However, the final chapter states something different: Cyanobacteria are found in thermo-acidic environments, living in biofilms in association with algae in endolithic layers, acidic soils, and stromatolites. I remain sceptical, but if it really were true, a convincing study on one population would surely merit a major - and probably much quoted - paper in Nature or Science.

Overall the book is clearly presented, with more or less standard formats for tables and figures. Some figures are in colour and the colour balance of general views looks reliable, though the size adopted for printing is sometimes small. More colour pictures would have been welcome in the case studies. The references are almost free of error, though the system adopted by the publisher for arranging the sequence of papers by a particular author can be tiresome for the reader when that author has many papers with diverse co-authors.

The editors are to be congratulated on assembling such a useful book which covers a wide spread of topics ranging from fundamental research to solving practical and sometimes very challenging problems. The book deserves to be widely available for anyone concerned with this topic.

Brian A. Whitton

School of Biological and Biomedical Sciences, Durham University, Durham DH1 3LE, UK 